\title{
Amino Acids and Their Derivatives in Pathogenesis and Treatment of Liver Diseases (Mini-Review)
}

\author{
Nefyodov $\mathrm{II}^{1 *}$, Karakosh $\mathrm{AJ}^{1}$, Alufaini $\mathrm{MA}^{1}$, Karavay $\mathrm{PA}^{2}$ and Karavay $\mathrm{NL}^{2}$ \\ ${ }^{1}$ Yanka Kupala Grodno State University, Belarus \\ ${ }^{2}$ Grodno State Regional Hospital, Belarus
}

*Corresponding author: Nefyodov II, Yanka Kupala Grodno State University, Belarus

\begin{tabular}{|c|c|}
\hline ARTICLE INFO & ABSTRACT \\
\hline Received: 蔧 November 24, 2019 & Keywords: Amino Acids; Derivatives; Liver Pathology \\
\hline Published: 慧December 02, 2019 & $\begin{array}{l}\text { Abbreviations: BCAA: Branched Chain Hydrocarbon Amino Acids; AAA: Aromatic } \\
\text { Amino Acid Metabolism: NE: Non-Essential }\end{array}$ \\
\hline
\end{tabular}

Citation: Nefyodov II, Karakosh AJ, Alufaini MA, Karavay PA, Karavay NL. Amino Acids and Their Derivatives in Pathogenesis and Treatment of Liver Diseases (MiniReview). Biomed J Sci \& Tech Res 23(3)2019. BJSTR. MS.ID.003904.

\section{Mini Review}

A mini review of literature data on the mechanisms of formation of the stock of free amino acids and their derivatives in liver pathology and methods for correcting metabolic imbalance. The importance of amino acids in the biosynthesis of protein and highly active biological compounds was the main prerequisite for numerous studies of their content in body fluids and tissues in a wide variety of experimental and pathological situations. In the intermediate metabolism of amino acids and their derivatives, a connecting role is played by in the integration of the main metabolic flows [1-4]. The pool of free amino acids is represented by a rich set of metabolically and functionally interconnected compounds, with the concentrations being a regulatory factor at many key steps of metabolism [5,6].

In connection with the foregoing, study of the mechanisms of formation of the free amino acid pool in vivo is part of the most important problem of contemporary biochemistry and clinical medicine associated with targeted regulation of metabolic processes in the human body by biologically active natural compounds. Currently, the number of patients with pathology continues to grow, with metabolic disorders playing a leading role in the genesis of these pathologic states [4-6]. The most urgent in this case is the problem of the pathogenetic role of disorders in the metabolism of amino acids in hepatobiliary pathology, as well as the optimization of the use of individual amino acids or their artificial mixtures not only for replacement therapy, but also for targeted metabolic correction of liver diseases [6-17]. In addition to disturbances in the chain of reactions of carbohydrate, lipid and protein metabolisms characteristic of liver damage, a pronounced amino acid imbalance is observed in physiological fluids and tissues [18-20].

Thus, it was shown that an increase in blood methionine level and a decrease in its excretion during exogenous loads with this amino acid clearly correlate with clinical manifestations of diseases accompanied by impaired liver function [21-24]. In addition, the blood of patients with liver damage shows a decrease in the concentration of the most important methionine degradation product, cysteine, and a dramatic increase in the toxicity of methionine [25,26]. Normally, up to $10 \mathrm{~g}$ of S-adenosylmethionine is formed daily from methionine in the liver of humans in the 
S-adenosyl synthetase reaction. A decrease in its operating time, which leads to a depletion of the cysteine pool, not only exacerbates the negative nitrogen balance that develops as a result of liver dysfunction, but also prevents detoxification reactions [27-31]. The latter, as is known, are associated with transmethylation processes in which S-adenosylmethionine plays the role of a donor of $\mathrm{CH} 3$ groups, and with the formation of glutathione, the synthesis of which requires cysteine [32-35].

The search for ways to normalize the metabolism of sulfur-containing amino acids in the last decade was the result of the use of S-adenosylmethionine preparations for the treatment of hepatic pathology. It was found that about half the total pool of methionine in humans is catabolized in the liver, with $80 \%$ of it being converted to S-adenosylmethionine. Subsequently, it was proved that the latter methylates are not only proteins, histones, biogenic amines and hormones, but also phospholipids of cell membranes. Thus, $\mathrm{S}$-adenosylmethionine is able to increase the fluidity of the hepatocyte membranes. It is recommended as an additive in amino acid mixtures for parenteral nutrition. At present, the most famous commercial preparation of S-adenosylmethionine in Europe [36-39].

It has been shown that with pathology accompanied by liver damage and a decrease in the activity of oxidation of other substrates, the body can satisfy its energy requirements by $30-40 \%$ due to the oxidation of branched chain hydrocarbon amino acids (BCAA) - valine, leucine and isoleucine in peripheral tissues (the main muscle) and gluconeogenesis [1-6,12-16]. Activation of BCAA utilization along with their insufficient intake in such situations leads to a decrease in their level in blood plasma [12-16,40]. In addition, since the liver is the main site of aromatic amino acid metabolism (AAA), in these cases the phenylalanine hydroxylation rate and its conversion to tyrosine are reduced. The hydroxylation coefficient (phenylalanine/tyrosine ratio) increases with hepatic pathology. Disorders in the utilization of BCAA and AAA by the liver during its pathology gave rise to the use of the APC / AAA molar ratio to quantify the amino acid imbalance $[41,42]$.

Thus, the imbalance between the hepatic utilization of the BCAA and AAA is one of the signs of its pathology. The oral administration of BCAA mixtures for these purposes increases their level while reducing the AAA content in the blood plasma of patients with liver failure. In the same study, the feasibility of using BCAA in subclinical forms of hepatic encephalopathy was proved, and their purpose under any catabolic conditions in the postoperative period was justified since they stimulate protein biosynthesis in muscles and liver and inhibit proteolysis, reducing negative nitrogen balance $[43,44]$. The above served as the basis for the design and use for parenteral nutrition in hepatology of specialized amino acid mixtures enriched in BCAA. Theoretically, their purpose in hepatic pathology is justified by the catabolic orientation of metabolic processes, the ability of these amino acids to activate protein biosynthesis and eliminate amino acid imbalance [12-16].
The results of the clinical testing of the oral administration of BCAA served as the basis for production of the tablet form of a mixture of these amino acids that is highly authoritative in the field of creating new hepatoprotections by Dr. Falk [45-47].

A natural development of the "amino acid" correction of hepatic pathology was the design of a number of highly specialized amino sols with targeted action, characterized by a high content of BCAA and a minimum of AAA, methionine and histidine. At the same time, in such mixtures, the glycine concentration is reduced to $8 \%$, since the latter is one of the amino acids and acts as an inhibitory neuromodulator in the central nervous system, and to activate the detoxification and urea processes in them, the arginine content was increased to $13 \%$. Similar drugs are created and tested in our country (FO-80 or "hepatamine"). Such FO-80 mixtures were widely used abroad: Aminosteryl-Hepa (Germany), LevaminHepa (Finland), Ner-OU (Japan) [5]. One of the main objectives of drug therapy for liver damage is prevention of liver failure and encephalopathy complicating it. The metabolism of proteins and amino acids in the development of liver failure is disturbed in the first place. In $63 \%$ of cases, acute liver failure is accompanied by subclinical forms of hepatic encephalopathy [48-50]. In the pathogenesis of the latter, an impairment in the metabolism of amino acids is also given a leading place.

Thus, with the development of acute liver failure, azotemia is noted, the plasma content of ammonia is increased, and that of glutamine is increased in the cerebrospinal fluid, which indicates accumulation of ammonia in the brain. Along with the activation of protein degradation processes in the intestine and in the liver, the urea formation cycle and AAA catabolism are inhibited and the activation of BCAA degradation in the muscles occurs. An increase in the concentration of ammonia in the brain activates glycolysis and inhibits the tricarboxylic acid cycle, causing a decrease in energy production. As a result of this, there is a disturbance in the formation of excitatory amino acids glutamate and aspartate in neurons with the formation of an excess of inhibitory neuromodulator glutamine. In addition, this leads to a disturbed synthesis of gamma-aminobutyrate. As a result, the balance of excitatory and inhibitory amino acids changes. The effects of ammonia in the brain are potentiated by neurotoxic products formed during the breakdown of AAA, and the production of false neurotransmitters is activated. The end result of these metabolic disorders is dysfunction of the central nervous system with a predominance of inhibition processes in it.

Thus, hepatobiliary pathology is characterized by significant disturbances in the intermediate metabolism and a change in the content of free amino acids (especially sulfur-containing, AAA and BCAA) in the blood plasma and liver. Consequently, study of amino acids is a promising field of present-day hepatology based on the concept of the role of amino acids and their derivatives in the pathogenesis of liver damage and the use of drugs in hepatic 
pathology. The reason for the use of taurine in liver diseases was the relatively long-established ability of this compound to form paired bile acids [49,51]. For humans, taurine is an almost essential amino acid, and with prolonged parenteral nutrition or insufficient intake of it, disturbances arise in the conjugation of bile acids and lipid absorption. Therefore, the composition of artificial mixtures for baby food (Semilak, USA) or our Tonus-1 mixtures (Belarus), as well as amino sols used in pediatric practice (Vamin-Lact Sweden, Levamin-Lact - Finland), supplementary contains taurine in amounts that meet the daily requirements. At present, it has been shown that taurine, in addition to its participation in the synthesis of paired bile acids, is a neurotransmitter and modulator in the central nervous system, a regulator of membrane excitability in the heart, an agent that actively affects the endocrine and reproductive functions of animals, protecting cell membranes from toxic substances. All this put it in a number of effective means of influencing the functional systems of the body and aroused quite justified interest not only of biochemists and physiologists, but also of clinicians in this natural metabolite of the animal organism. A 4\% taurine solution under the name "Taufone" is used only in the form of eye drops and sub-conjunctival injections in ophthalmology as a stimulator of regeneration processes $[2,12]$.

In studying the special pharmaceutical and biological activity of taurine, it was established that the compound has hepatoprotective and radioprotective properties. So, prescribed in various doses and modes of administration, taurine increases the survival of animals, prevents depression of blood cells and weight coefficients of lymphoid organs. In the anti-radiation effect, it is not inferior to the reference drugs hexamine and cysteamine, comparing favorably with their low toxicity and the predicted absence of adverse reactions undesirable for the body, as well as the contraindication to use. It has been proven that taurine exhibits hepatoprotective properties: it activates metabolic processes in the liver, increases its resistance to pathogenic effects and activates the restoration of its functions in various injuries [2,12,52-54]. Taurine is slightly toxic, does not cumulate in the body, does not have an irritant effect, does not affect reproductive function and offspring, does not exhibit allergenic properties and does not adversely affect the immune system. With its chronic prescription, the changes occurring in morphological, physiological, and biochemical parameters are not damaging, reversible, and return to the initial level after drug withdrawal within 8-10 days [12].

Therefore, our efforts were focused on the study of the specific metabolic activity of taurine as a regulator of amino acid metabolism, hepatoprotective and radioprotective drug and a component of artificial amino acid mixtures. Ultimately, this part of the work was almost completed by the development for the tablet dosage form of this drug, and clinical trials of taurine tablets as hepatoprotective and radioprotective agents according to the specific indications for use are being completed in specialized clinics. In connection with the latter, it was especially important to study the mechanisms of biosynthesis, as well as the formation of an intracellular pool of sulfur-containing amino acids and a functionally active pool of the most important product of their degradation, taurine [1-3].

We have shown that a single intraperitoneal administration of taurine at a dose of $1 / 10$ LD50 causes an increase in the concentration of this compound in the liver and blood plasma of rats and a decrease in the levels of methionine, glycogenic amino acids, BCAA and AAA. In addition, in vitro taurine at concentrations of 106-10-7 M increases the antiradical activity of liver homogenates, their content of phosphatidylcholine, phosphoethanolamine and reduces the level of ethanolamine [6]. Supplementary in vivo administration of taurine increased the concentrations of reduced glutathione, CoA, 2-oxoglutarate, the NAD/NADH ratio, activated mitochondrial decarboxylases and transaminases and reduced the concentration of glutamic acid, the ratio of BCAA / AAA, acetylCoA / CoA in the liver. All of the above proves that increasing the concentration of taurine activates glycolysis and the utilization of carbon skeletons of amino acids in the tricarboxylic acid cycle in the liver [12]. Metabolic prerequisites arising against the background of an increased content of taurine in the body, thereby prove the advisability of including this compound in the composition of artificial mixtures of amino acids for parenteral nutrition [55-57].

A statistical model constructed for rat liver revealed a dependence of the level of BCAA on taurine content, which suggests its effect on glucose-alanine cycle activity, gluconeogenesis, and utilization of these amino acids in the citric acid cycle [5]. Based on the mathematical models created for the liver and blood plasma, it can be assumed that an increase in the concentration of taurine in the blood or liver upon activation of its synthesis or against an exogenous load will contribute to a decrease in the level of glycogenic amino acids [6,12]. Studies were also carried out of the patterns of formation of the amino acid pool in the liver, blood plasma and bile of patients against the background of functionally reversible injuries of the hepatobiliary system in acute and chronic cholecystitis. In our studies [1-6,12-16], it was shown that both acute and chronic forms of cholecystitis are accompanied by hyper aminoacidemia mainly due to glycogenic, aromatic and sulfurcontaining, as well as amino acids and their derivatives, markers of liver antitoxic function (urea, ammonia, gamma-aminobutyrate). Changes in the content of these compounds were more pronounced in the chronic form of the disease, especially due to an increase in the total pool of sulfur-containing amino acids.

The dependence found by us was confirmed by the high efficiency of the use of the Vamin amino amine in the clinic. Metabolic correction of changes induced by operating trauma and inflammation of the gallbladder was effective in the absence of pronounced metabolic, functional and morphological changes in the liver and contributed to a decrease in the frequency of postoperative complications [1-6,58-62]. In the liver of animals with experimental cholestasis, a pronounced tendency to an increase in the total stock 
of free amino acids was observed along with the almost fivefold decrease in the ratio of essential amino acids to non-essential (NE) ones. It is characteristic that these changes related primarily to glycogenic amino acids, a metabolic disturbance in which in the liver is one of the characteristic signs that occur even at early stages of hepatobiliary pathology. On enrichment of the stock with free sulfur-containing amino acids and their derivatives, a three-fold decrease in the Fisher index (BCAA/AAA) was clearly noticed [3].

An additional administration of taurine in experimental cholestasis had a normalizing effect on the levels of the studied compounds in the liver and blood plasma of animals. From the results reflecting the regularities of the formation of a pool of free amino acids in hepatocytes of control and experimental animals, it is obvious that the metabolic activity of hepatocytes isolated from the "cholestatic" liver was reduced with respect to de novo amino acid synthesis [5]. In the situation of experimental cholestasis, we revealed the general patterns of the formation of amino acid imbalance at the tissue (liver) and cellular (isolated hepatocytes) levels and found metabolic preconditions justifying the feasibility of including taurine in the composition of artificial mixtures of amino acids for parenteral nutrition in extrahepatic cholestasis [12]. The patterns of formation of the amino acid pool underdeveloped liver failure were studied by us at the stages of surgical elimination of biliary hypertension in 147 patients with subhepatic jaundice. The amino acid imbalance in the blood plasma of this group of patients was characterized by hyper aminoacidemia that was in equal measure due to both NEAA and EAA, a drastic decrease in the concentration of BCAA and a reduction in the ratio of BCAA /AAA.

Characteristic of blood plasma was a dramatic increase in the concentration of sulfur-containing amino acids or formation of paired compounds with bile acids or amino acids. Changes in the content of the studied compounds in the liver due to its insufficiency as a whole indicate an inhibition of reactions of amino acid synthesis in the liver, their entry into bile, and a decrease in the activity of enterohepatic recirculation [4]. Thus, extrahepatic cholestasis under developing liver failure is characterized by a pronounced amino acid imbalance which is formed mainly due to a change in the levels of glycogenic and sulfur-containing amino acids. A linear discriminant analysis of the amino acid pool of liver biopsy samples of these patients showed that, despite the increase in the content of precursors, the level of taurine did not essentially differ from the control values. Obviously, in such a situation, an increase in the concentration of taurine in the liver can be achieved only due to its exogenous administration. Mathematical modeling of the formation of the free amino acid pool in the liver justifies the feasibility of additional exogenous administration of taurine in hepatobiliary pathology [12].

From the first day after application of a laparoscopic cholecystomy, it turned out that the introduction into the bile ducts of $60 \mathrm{ml}$ of a $4 \%$ solution of taurine (Taufone), dissolved in $500 \mathrm{ml}$ of an isotonic solution of sodium chloride, under the pressure of a 140-180 mm water column in combination with intravenous administration of $400 \mathrm{ml}$ Polyamine led to controlled decompression, correction of amino acid imbalance and a significant decrease in the manifestations of liver failure [1]. Thus, against the background of functionally reversible or morphological changes in the liver combined with hepatobiliary pathology, qualitatively similar metabolic disorders are formed in humans, leading to an amino acid imbalance and an increase in the concentration of sulfur-containing, aromatic and glycogenic amino acids in the liver and blood plasma.

\section{Conclusion}

Based on the results, we substantiated the effectiveness of using amino sols enriched with sulfur-containing amino acids or taurine to normalize the amino acid imbalance and the functional state of the liver, in order to diagnose and treat the initial stages of its damage. The changes in the level of free amino acids of the liver, blood plasma and bile are quite specific and informative for assessing the functional state of the liver, diagnosing and optimizing the metabolic correction of hepatobiliary pathology, and the prescription of taurine and special artificial mixtures of amino acids in the pathology studied aids in normalization of the amino acid imbalance and clinical and biochemical parameters as well as reduces the frequency of postoperative complications and the length of stay of patients in hospital.

\section{Acknowledgement}

None.

\section{Conflict of Interest}

No conflict of interest.

\section{References}

1. Nefyodov LI (1992) DSci dissertation abstract (biochemistry) Formation of the stock of free amino acids and their derivatives under conditions of metabolic imbalance. Institute of Radiobiology of the Academy of Sciences of Belarus, Minsk, p 32.

2. Nefyodov LI (1999) Mechanisms of regulatory effects and strategy of using amino acids and their derivatives as effective agents for metabolic therapy and medicinal preparations Proc of Internat. Symp. Biological activity and transport of drugs. L Nefydov, Grodno, (Eds.) pp. 189.

3. Nefyodov L (1998) Mechanisms of regulation of metabolic balance: results and prospects for the use of amino acids and their compositions as universal biologically active natural regulators of directional action and effective drugs. Vestsi NAS Belarus. Ser. bial navuk. pp. 61-69.

4. (1996) Amino Acids and Their Derivatives (chemistry, biochemistry, pharmacology, medicine), L Nefyodov (Eds.)., Proc of Internat. Symp; Grodno, p.125.

5. Nefyodov LI, Karavay PA, Karavay NL (2014) Regulatory action of free amino acids and development on the basis of highly of substances infusion solutions with pathogenetic deterministic composition. Laboratory diagnosis Eastern Europe 3: 111-115.

6. Nefyodov LI (2010) The results of biochemical research and development of nitrogen-containing compounds of natural origin: methodology of exploitation of biological properties as universal natural regulators of metabolism and drugs. 
7. (1992) Wrights Liver and Biliary Disease (Pathophysiology, Diagnosis and Management),(Eds.), GH Millward Sadler, R Wright, MJP Arthur Trird, (Eds.)., W.B. Saunders Company, Ltd, USA, 1-2: p.1540 .

8. (1992) Schaffner F, Cholestasis In "Wright's Liver and Biliary Discase", GH Milward Sadler, R Wrigth, MJP Arthur, (Eds.)., pp. 371-396.

9. (1990) Amino Acids (Chemistry, Biology, Medicine). Lubec C, Rosental JA, (Eds.)., Escom, NY, USA, pp. 1196.

10. Shadi S, Yarandi, Vivian M, Zhao Gautam Hebbar, Thomas R Zieglera (2011) Amino acid composition in parenteral nutrition: what is the evidence? Curr Opin Clin Nutr Metab Care 14(1): 75-82.

11. Nefyodov LI (2001) Planowa regulacja równowagi metabolizmu aminokwasami i strategia ich zastosowania w jakości nowych efektywnych preparatów leczniczych, XXXVII Zjazd Polskiego towarzystwa biochemicznego. Torun, 10-14 IX 2001. s.327

12. Nefyodov L (1999) Taurine (biochemistry, pharmacology, medical application) Grodno RIPH. p. 145.

13. (1999) Biological activity and transport of drugs. L Nefyodov, (Eds.)., Proc of Internat Symp, Grodno. p.189.

14. (2000) VI Ordinary General Assembly Society of Biochemistry of Belarus. L Nefyodov, (Eds.)., Proc of Internat. Symp; Grodno. p. 225.

15. (2001) Amino acids and their derivatives in biology and medicine. L Nefyodov (Eds.)., Proc of Internat. Symp, Grodno. p. 124.

16. Karavay PA, Nefyodov LI, Karavay NL (2016) Amino acids in Metabolomics: Perspective for the Use of Regulatory effects of Fee Amino Acids in the Creation on their Basis of Infusion Solutions//International Journal of Hematology \& Therapy 2: 1-2.

17. Da Young Lee, Eun Hee Kim (2019) Therapeutic Effects of Amino Acids in Liver Diseases: Current Studies and Future Perspectives J Cancer Prev 24(2): 72-78

18. Meijer AJ (2003) Amino acids as regulators and components of nonproteinogenic pathways. J Nutr 133(6): 2057S-62S.10.1093.

19. Wolf PL (1999) Biochemical diagnosis of liver disease. Indian J Clin Biochem 14: 59-90.10.1007/BF02869152.

20. Freudenberg A, Petzke KJ, Klaus S (2013) Dietary L-leucine and L-alanine supplementation have similar acute effects in the prevention of high-fat diet-induced obesity. Amino Acids 44(2): 519-528.

21. Wu G (2013) Functional amino acids in nutrition and health. Amino Acids 45: 407-411.

22. Wu G, Wu Z, Dai Z, Yang Y, Wang W, et al. (2013) Dietary requirements of "nutritionally non-essential amino acids" by animals and humans Amino Acids 44(4): 1107-1113.

23. Mato JM Martínez Chantar ML, Lu SC (2008) Methionine metabolism and liver disease. Annu Rev Nutr 28: 273-293.

24. Young Suk Jung (2015) Metabolism of Sulfur-Containing Amino Acids in the Liver: A Link between Hepatic Injury and Recovery J-STAGE Biological and Pharmaceutical 38 (7): 971-914.

25. (1990) Amino Acids (Chemistry, Biology, Medicine). Lubec C, Rosental JA, (Edn.)., Escom, NY, USA, pp. 1196.

26. Chawla RK, Bankovsky HL, Calambos JT (1990) Biochemistry and Pharmacology of SAM and retionale for use in liver disease. Drugs 40 (3): 98-110.

27. Yose MM, Corales F, Martin Duce A (1990) Mechanisms and consequences of the imparied trans-sulfuration pathway in the liver deasese: path I. Biochemical applications. Drugs 40 (3): 58-64.

28. Kaye GL (1990) Metabolism of Exogenous SAM in patients with liver disease. Drugs 40 (3): 124-128.

29. Placencia C, Careia MA, Torres C (1991) Efficacy of parenteral SAM in a case of intrahepatic cholestasis, induced by total parenteral nutrition. J Hepatol 13 (2): 104-110.
30. NefyodovLI (2001) Target - oriented regulation of metabolic equilibrium by amino acids and strategy of their application as drugs with directional effects. L.I. Nefyodov (Eds.)., XXXVII Zjazd Polskiego towarzystwa biochemicznego, Torun, 10-14 IX: p. 327.

31. Berlanga A, Guiu Jurado E, Porras JA, Auguet T (2014) Molecular pathways in non-alcoholic fatty liver disease. Clin Exp Gastroenterol 7: 221-239.

32. Dejong $\mathrm{CH}$, Van de Poll MC, Soeters PB, Jalan R, Olde Damink SW (2007) Aromatic amino acid metabolism during liver failure. J Nutr 137(6): 1579S-85S; discussion 1597S-8S.10.1093.

33. Brosnan JT (2001) Amino acids, then and now: a reflection on Sir Hans Krebs' contribution to nitrogen metabolism. IUBMB Life 52(6): 265-270.

34. Tajiri K, Shimizu Y (2018) Branched-chain amino acids in liver diseases. Transl Gastroenterol Hepatol 3: 47.

35. Abumrad NN, Geer R, Blair J (1990) Sources of hepatic Glutamine synthesis in vivo. Biol Chem 371: 291-305

36. Aebi S, Lautenburg BH (1991) Hepatic Glutathione is regulated by the availability at Cysteine and not by feedback inhibition. J of Hepatol 13 (2): 3 .

37. Ballatori N (1990) Hepatic transport and interorgan metabolism of Glutathione. Biol Chem 371: 291-305.

38. Bazon P (1990) Plasmopheresis and BCAA in the therapy of hepatic encephalopathy. Therapy of Hepatobiliary Deseases. Halle p. 29

39. (1986) Chronic Liver Disease. Dianzani MU, Gentilini P, (Eds.)., Karger, Basel, pp.398.

40. Erikson LS (1992) BCAA in the treatment of hepatic encephalopathy Therapy of liver diseases Rodes J, Arroyoy (Eds.)., Doyma pp. 292-301.

41. Haussinger D (1990) Nitrogen metabolism in liver: structure and functional organization and physiological relevance. Biochem J 267(2): 281-290.

42. Reichen J (1992) Treatment of galdstones and cholestasis: introduction. Therapy in liver disorders, Rodes J, Aroya V, (Eds.)., Doyma, pp. 41-44.

43. Shlenker T, Readsch R, Plachky J (1991) Glycine and Taurine conjugation of URSO excreted into bile during infusion of unconjugated URSO in rat. J Hepatol 13 (2): 170

44. Sholmerich J, Holstege A (1990)Aetiology and Pathophysiology of Chromic Liver Disorders. Druga 40 (3): 3-22.

45. Smith RJ, Wilmore DW (1990) Glutamine metabolism and glutamine requirements: implications for parenteral and enteral nutrition. Biol Chem 371: 291-305.

46. Stavinoha MW, Soloway RD (1990) Current Therapy of Chronic Liver Disease. Drugs 39 (6):814-840.

47. (1978) Taurine and Neurological Disorders. Barbeau A, Nuxtable A, (Edn.)., Raven Press, NY, USA, pp. 468.

48. Therapy liver disorders, Rodes J, Aroya V, Doyma, (Eds.)., Spain, pp. 451

49.Zenezoli ML (1992) Pathophysiology of hepatic encephalopathy. Therapy of Liver Disorders, Rodes J, Arroyo V, Doyma, (Eds.)., pp. 270 276

50. Da Young Lee, Eun Hee Kim (2019) Therapeutic Effects of Amino Acids in Liver Diseases: Current Studies and Future Perspectives / Journal of Cancer Prevention 24(2): 72-78.

51. Berlanga A, Guiu Jurado E, Porras JA, Auguet T (2014) Molecular pathways in non-alcoholic fatty liver disease. Clin Exp Gastroenterol 7: 221-239.

52. Wu G (2009) Amino acids: metabolism, functions, and nutrition. Amino Acids 37(1): 1-17

53. Lukey MJ, Katt WP, Cerione RA (2017) Targeting amino acid metabolism for cancer therapy. Drug Discov Today 22(5): 796-804. 
54. Dejong CH, Van de Poll MC, Soeters PB, Jalan R, Olde Damink SW (2007) Aromatic amino acid metabolism during liver failure. J Nutr 137(1) 1579S-85S

55. Meijer AJ (2003) Amino acids as regulators and components of nonproteinogenic pathways. J Nutr 133(6): 2057S-62S.

56. Brosnan JT (2001) Amino acids, then and now: a reflection on Sir Hans Krebs' contribution to nitrogen metabolism. IUBMB Life 52(6): 265-270.

57. Wu G (2013) Functional amino acids in nutrition and health. Amino Acids 45(3): 407-411.

58. Wu G, Wu Z, Dai Z, Yang Y, Wang W, et al. (2013) Dietary requirements of nutritionally non-essential amino acids by animals and humans. Amino Acids 44(4): 1107-1113.

\section{ISSN: 2574-1241}

DOI: 10.26717/BJSTR.2019.23.003904

Nefyodov II. Biomed J Sci \& Tech Res

(C) This work is licensed under Creative

Submission Link: https://biomedres.us/submit-manuscript.php
59. Yanni AE, Agrogiannis G, Nomikos T, Fragopoulou E, Pantopoulou A, et al. (2010) Oral supplementation with L-aspartate and L-glutamate inhibits atherogenesis and fatty liver disease in cholesterol-fed rabbit. Amino Acids 38(5): 1323-1331.

60. Dowman JK, Tomlinson JW, Newsome PN (2010) Pathogenesis of nonalcoholic fatty liver disease. QJM 103(2): 71-83.

61. Van den Berghe G (1991) The role of the liver in metabolic homeostasis: implications for inborn errors of metabolism. J Inherit Metab Dis 14(4): 407-420.

62. Zhang F, Zhao S, Yan W, Xia Y, Chen X, et al. (2016) Branched chain amino acids cause liver injury in obese/diabetic mice by promoting adipocyte lipolysis and inhibiting hepatic autophagy. E Biomedicine 13: 157-167.

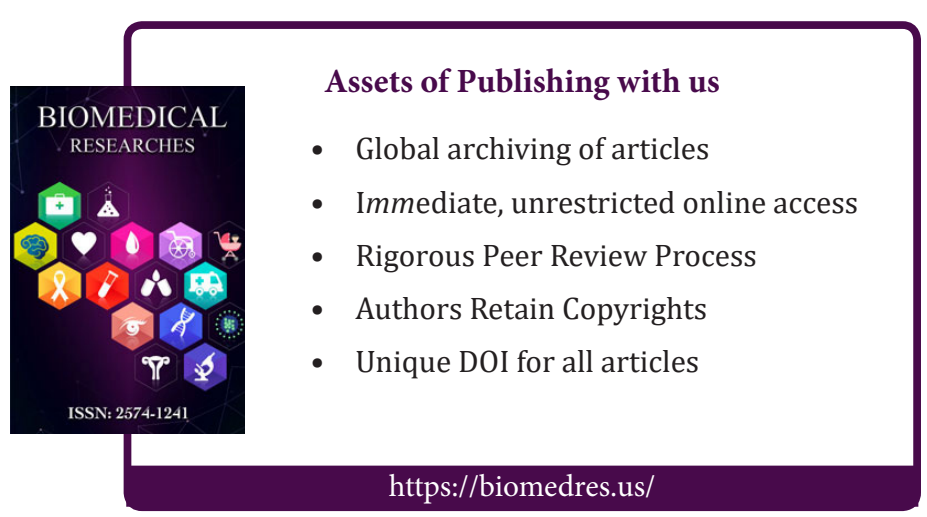

